\title{
5-Nitrotetrazol and 1,2,4-Oxadiazole Methylene-Bridged Energetic Compounds: Synthesis, Crystal Structures and Performances
}

\author{
Jiarong Zhang ${ }^{1,2}$, Fuqiang Bi ${ }^{1,3, *}$, Zhi Yang ${ }^{2}$, Qi Xue ${ }^{1,3}$ and Bozhou Wang ${ }^{1,3, *}$ \\ 1 Xi'an Modern Chemistry Research Institute, Xi'an 710065, China; sonia610@126.com (J.Z.); \\ xueq704@163.com (Q.X.) \\ 2 School of Chemistry and Chemical Engineering, Beijing Institute of Technology, Beijing 100081, China; \\ zhiyang@bit.edu.cn \\ 3 State Key Laoratory of Fluorine \& Nitrogen Chemicals, Xi'an 710065, China \\ * Correspondence: bifuqiang@gmail.com (F.B.); wbz600@163.com (B.W.); Tel.: +86-029-88294197 (F.B. \& B.W.)
}

check for updates

Citation: Zhang, J.; Bi, F.; Yang, Z.; Xue, Q.; Wang, B. 5-Nitrotetrazol and 1,2,4-Oxadiazole Methylene-Bridged Energetic Compounds: Synthesis, Crystal Structures and Performances. Molecules 2021, 26, 7072. https:// doi.org/10.3390/molecules26237072

Academic Editor: Weihua Zhu

Received: 19 October 2021

Accepted: 19 November 2021

Published: 23 November 2021

Publisher's Note: MDPI stays neutral with regard to jurisdictional claims in published maps and institutional affiliations.

Copyright: (c) 2021 by the authors. Licensee MDPI, Basel, Switzerland. This article is an open access article distributed under the terms and conditions of the Creative Commons Attribution (CC BY) license (https:// creativecommons.org/licenses/by/ $4.0 /)$.
Abstract: A new structural type for melt cast materials was designed by linking nitrotetrazole ring with 1,2,4-oxadiazole through a N-CH$-\mathrm{C}$ bridge for the first time. Three $\mathrm{N}-\mathrm{CH}_{2}-\mathrm{C}$ linkage bridged energetic compounds, including 3-((5-nitro-2H-tetrazol-2-yl) methyl)-1,2,4-oxadiazole (NTOM), 3-((5-nitro-2H-tetrazol-2-yl)methyl)-5-(trifluoromethyl)-1,2,4 -oxadiazole (NTOF) and 3-((5nitro-2H-tetrazol-2-yl)methyl)-5-amine-1,2,4-oxadiazole (NTOA), were designed and synthesized through a two-step reaction by using 2-(5-nitro-2H-tetrazole -2-yl)acetonitrile as the starting material. The synthesized compounds were fully characterized by NMR $\left({ }^{1} \mathrm{H},{ }^{13} \mathrm{C}\right)$, IR spectroscopy and elemental analysis. The single crystals of NTOM, NTOF and NTOA were successfully obtained and investigated by single-crystal X-ray diffraction. The thermal stabilities of these compounds were evaluated by DSC-TG measurements, and their apparent activation energies were calculated by Kissinger and Ozawa methods. The crystal densities of the three compounds were between $1.66 \mathrm{~g} / \mathrm{cm}^{3}$ (NTOA) and $1.87 \mathrm{~g} / \mathrm{cm}^{3}$ (NTOF). The impact and friction sensitivities were measured by standard BAM fall-hammer techniques, and their detonation performances were computed using the EXPLO 5 (v. 6.04) program. The detonation velocities of the three compounds are between $7271 \mathrm{~m} / \mathrm{s}$ (NTOF) and $7909 \mathrm{~m} / \mathrm{s}(\mathrm{NTOM})$. The impact sensitivities are $>40 \mathrm{~J}$, and the friction sensitivities are $>360 \mathrm{~N}$. NTOM, NTOF and NTOA are thermally stable, with decomposition points $>240{ }^{\circ} \mathrm{C}$. The melting points of NTOM and NTOF are $82.6^{\circ} \mathrm{C}$ and $71.7^{\circ} \mathrm{C}$, respectively. Hence, they possess potential to be used as melt cast materials with good thermal stabilities and better detonation performances than TNT.

Keywords: nitrotetrazole; 1,2,4-oxadiazole; methylene-bridged energetic compound; synthesis; performances

\section{Introduction}

Melt cast explosives are widely used in military and civilian fields such as grenades, mortars, warheads and antipersonnel mines [1]. Although the melting points of melt cast explosives are generally between 70 and $120^{\circ} \mathrm{C}$, a compound possessing melting point below $100{ }^{\circ} \mathrm{C}$ is ideal in order to use steam for low-cost melting operations [2]. 2,4,6-Trinitrotoluene (TNT) and dinitroanisole (DNAN) are two kinds of widely investigated and applied melt cast materials. However, their further applications are limited by their relative shortcomings, such as the toxicity and environmental problems of TNT $[3,4]$ and low detonation performances of DNAN [5,6]. Therefore, there is continued interest in developing new melt cast materials with better explosive performances.

In the past decade, significant progress has been made in the field of melt cast explosives. Researchers have found that the 1,2,4-oxadiazole skeleton is promising for the construction of new high explosives with balanced detonation and safety properties [7-10]. A 
lot of melt cast energetic materials have been synthesized based on 1,2,4-oxadiazole, such as 3,5-bis(4-nitrofurazan-3-yl)-1,2,4-oxadiazole (LLM-191) [11], 3-(4-amino-1,2,5-oxadiazol-3yl)-5-(4-nitro-1,2,5-oxadiazol-3-yl)-1,2,4-oxadiazole (LLM-192) [11], 3-(4-nitro-1,2,5-oxadiazol3-yl)-1,2,4-oxadiazol-5-amine (LLM-201) [12], bis(1,2,4-oxadiazolyl)furoxan (BOF) [13] and bis(1,2,4-oxadiazole)bis(methylene) dinitrate (BODN) [14] (Figure 1a). In recent years, several design strategies on the structures and properties of melt cast explosives have been developed. For example, the combination of 1,2,4-oxadiazoles with other heterocyclic rings bearing energetic groups that exhibit melt-castable characteristics, the introduction of bridged alkyl chains in heterocycles and the incorporation of fluorine or trifluoromethyl groups on heterocyclic rings are effective methods for the construction of highly energetic melt cast materials [15]. Recently, Tian Lu [16] et al. reported a low melting point compound bis(5-(trinitromethyl)-1,2,4-oxadiazol-3-yl)methane $\left(T_{\mathrm{m}}: 52{ }^{\circ} \mathrm{C}\right)$, which is composed of two 1,2,4-oxadizole rings bridged by $\mathrm{C}-\mathrm{CH}_{2}-\mathrm{C}$ linkage (Figure 1b). Although bis(5(trinitromethyl)-1,2,4-oxadiazol-3-yl)methane possesses good detonation performances ( $D$ : $9053 \mathrm{~m} / \mathrm{s}, P: 37.4 \mathrm{GPa}$ ), its mechanical sensitivities are relatively high (IS: $12.5 \mathrm{~J}, F S: 72 \mathrm{~N}$ ), and the decomposition point is only $117^{\circ} \mathrm{C}$. Hence, this compound is not thermally stable, and its wide application is limited.

\section{Previous work}

a)

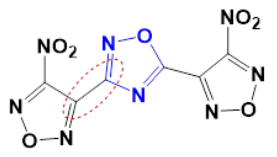

LLM-191

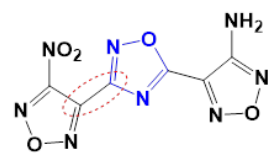

LLM-192<smiles>Nc1nc(-c2nonc2[N+](=O)[O-])no1</smiles>

LLM-201

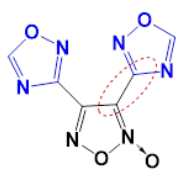

BOF<smiles>O=[N+]OCc1nc(-c2noc(CO[N+](=O)[O-])n2)no1</smiles>

BODN

b)

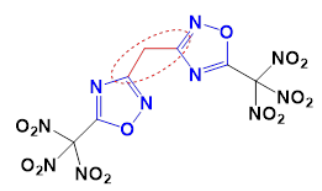

\section{This work}

c)

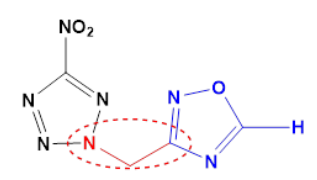

NTOM<smiles></smiles>

NTOA<smiles></smiles>

$\mathrm{N}-\mathrm{CH}_{2}-\mathrm{C}$ linkage

NTOF

Figure 1. (a) Previous 1,2,4-oxadiazole energetic materials with C-C bond linkage; (b) methylene bridged 1,2,4-oxadiazole melt cast material with $\mathrm{C}-\mathrm{CH}_{2}-\mathrm{C}$ linkage; (c) methylene bridged 1,2,4-oxadiazole melt cast material with $\mathrm{N}-\mathrm{CH}_{2}-\mathrm{C}$ linkage.

Herein, for the first time, we designed a new kind of structure by linking 1,2,4oxadiazole and nitrotetrazole ring via $\mathrm{N}-\mathrm{CH}_{2}-\mathrm{C}$ linkage. We expect that this could be a promising new strategy for constructing energetic compounds that possess good detonation parameters, better thermal stabilities and lower sensitivity toward impact and friction. In 2019, we firstly synthesized NTOA [17], but detailed structural characteristics and performance investigations were not investigated. Herein, based on our previous studies, two new energetic compounds (NTOF and NTOM) were firstly designed and 
synthesized (Figure 1c). All of the synthesized compounds in this study were characterized by nuclear magnetic resonance (NMR) and infrared (IR) spectroscopy. X-ray crystallographic measurements of the three compounds were performed, providing insight into structural characteristics as well as intramolecular and intermolecular interactions of these compounds. The thermal stabilities were evaluated by DSC-TG measurements, and the detonation and sensitivity performances were investigated comprehensively.

\section{Results and Discussions}

\subsection{Synthesis}

5-nitrotetrazol-3-acetonitrile (1) was prepared according to the method we developed previously [17]. The intermediate compound N'-hydroxy-2-(5-nitro-2H-tetrazol2-yl)acetimidamide (NTAA) was synthesized from compound one in the presence of hydroxylamine hydrochloride with a yield of $96 \%$. Based on NTAA, three methyl-bridged nitrotetrazole and 1,2,4-isofurazan compounds including NTOM, NTOF and NTOA were synthesized with yields of $82 \%, 79 \%$ and $62 \%$, respectively. In order to synthesize energetic compounds with better energy performances, we tried to oxidize and nitrate the amino group of NTOA to the nitro or nitramine group, but failed to obtain the targeted compounds (Scheme 1).

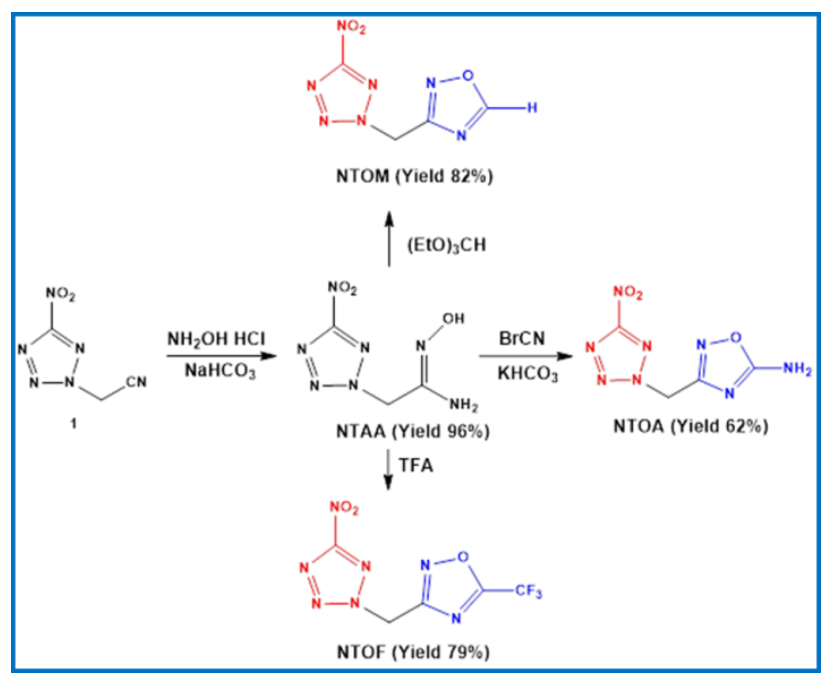

Scheme 1. The synthesis approaches of NTOM, NTOF and NTOA.

\subsection{X-ray Crystallography}

The crystal structures of NTOM, NTOF and NTOA were obtained and analysed by X-ray single crystal diffraction (Figure 2). The crystal data and structure refinement parameters were given in Tables S1-S4 in the SI.

(a)

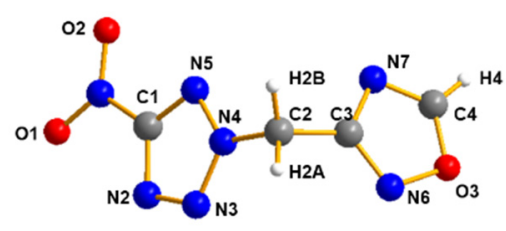

(b)

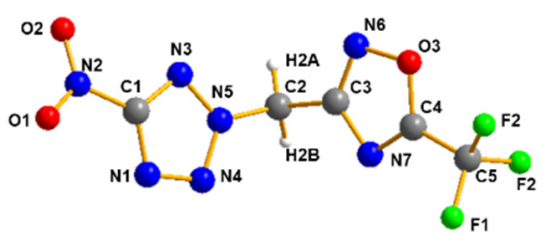

(c)

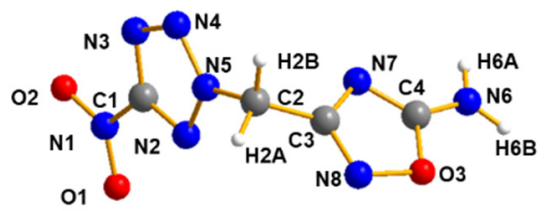

Figure 2. Single-crystal X-ray structures of NTOM (a), NTOF (b) and NTOA (c). 
NTOM, NTOF and NTOA crystalized in the monoclinic system and contained four molecules in a unit cell. The space group of NTOM, NTOF and NTOA are P(1)2(1)/n(1), $\mathrm{P} 2(1) / \mathrm{c}$ and P2(1)/n, respectively. The crystal density of NTOM is $1.76 \mathrm{~g} \cdot \mathrm{cm}^{-3}$ at $296(2) \mathrm{K}$. After introduction of $-\mathrm{CF}_{3}$, crystal density was obviously improved to $1.87 \mathrm{~g} \cdot \mathrm{cm}^{-3}$. However, the introduction of $-\mathrm{NH}_{2}$ into NTOM causes crystal density of NTOA to decrease to $1.66 \mathrm{~g} \cdot \mathrm{cm}^{-3}$. As illustrated in Figure 2c, the amino group and 1,2,4-oxadiazole are in the same plane, and the atoms in 5-nitrotetrazole are essentially planar with very small torsion angle $\left(-1.76^{\circ}\right)$ of N3-C1-N1-O2. Meanwhile, the C-N bond length and the N-N bond length in oxadiazole and tetrazole rings are found to be shorter than the normal $\mathrm{C}-\mathrm{N}$ single bond $(1.47 \AA)$ and longer than the $\mathrm{C}=\mathrm{N}$ double bond $(1.22 \AA)$. These results indicate that electronic conjugation is formed in amino-1,2,4-oxadiazole and 5-nitrotetrazole structure.

From Figure 3a, there are no typical hydrogen bonds formed in NTOM, and each NTOM molecule exists independently. The stacking diagram (Figure 3b) indicated that two adjacent NTOM molecules in one layer were arranged in reverse and the NTOM molecules in different layers occluded with each other; thus, the molecular arrangement is relatively compact. In NTOF (Figure 3c,d), the hydrogen bond C2-H2A ... F1 causes the molecules between two adjacent layers to be more closely arranged. Meanwhile, due to the introduction of fluorine atoms, the density of NTOM further increased, in comparison with NTOM. Unlike NTOM and NTOF, there are two kinds of typical hydrogen bonds in NTOA. The hand-in-hand intermolecular hydrogen bond N6-H6B ... O1 (Figure 4a) constructs the 2D layer structure of NTOA, and the adjacent layers are connected by the face-to-face hydrogen bond N6-H6A ... N7 (Figure 4b). The length of both the two hydrogen bonds in NTOA is shorter than $3.0 \AA$, which are within the range of strong hydrogen bonds. The presence of a large number of hydrogen bonds is beneficial for improving the density and stability of NTOA. Due to the -CH2- group connection, the dihedral angle of N7-C3-C2-N5 is $49.71^{\circ}$, and the stacked structure of NTOA is polyline-like (Figure $4 \mathrm{c}$ ).
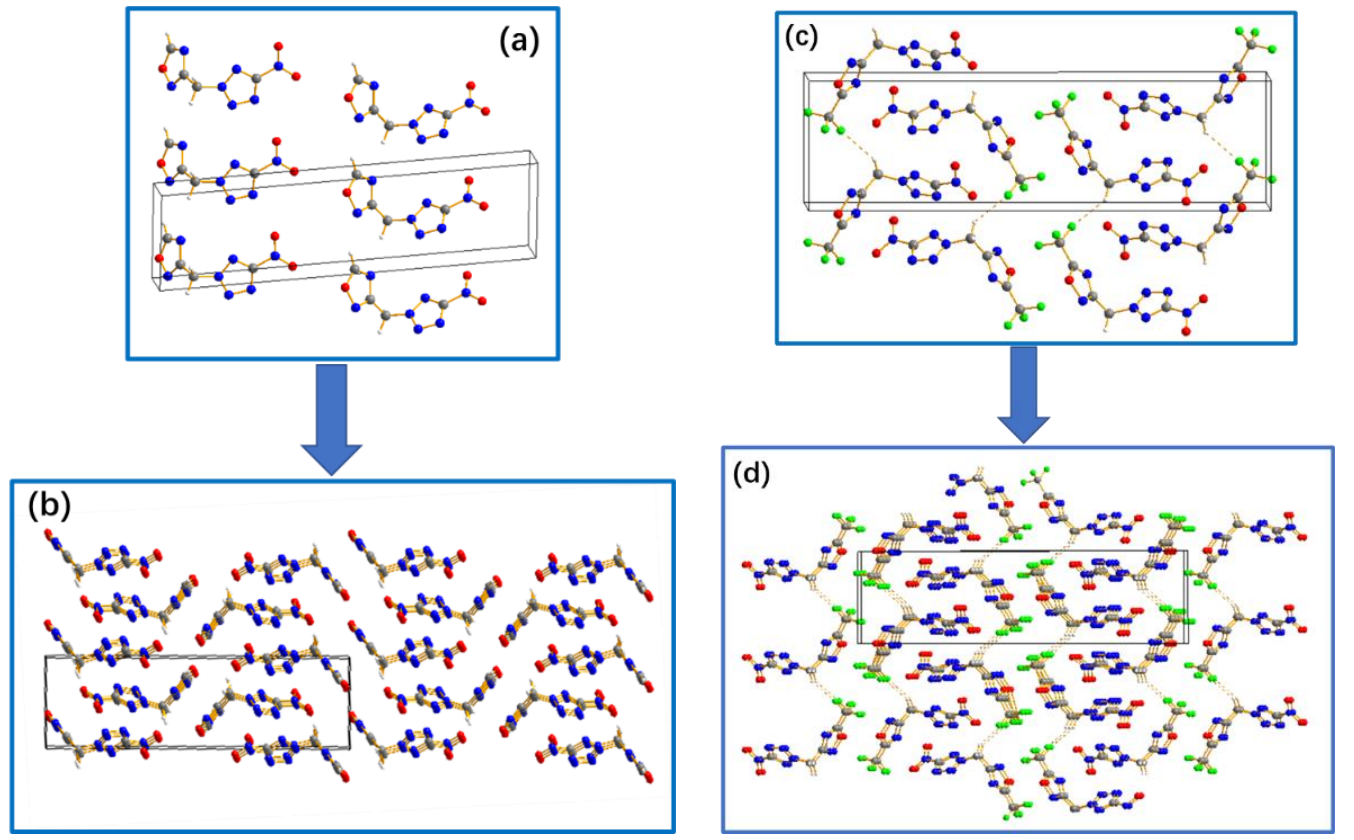

Figure 3. (a) Two-dimensional image of NTOM; (b) stacking diagram of NTOM; (c) two-dimensional image of NTOF; (d) stacking diagram of NTOF. 


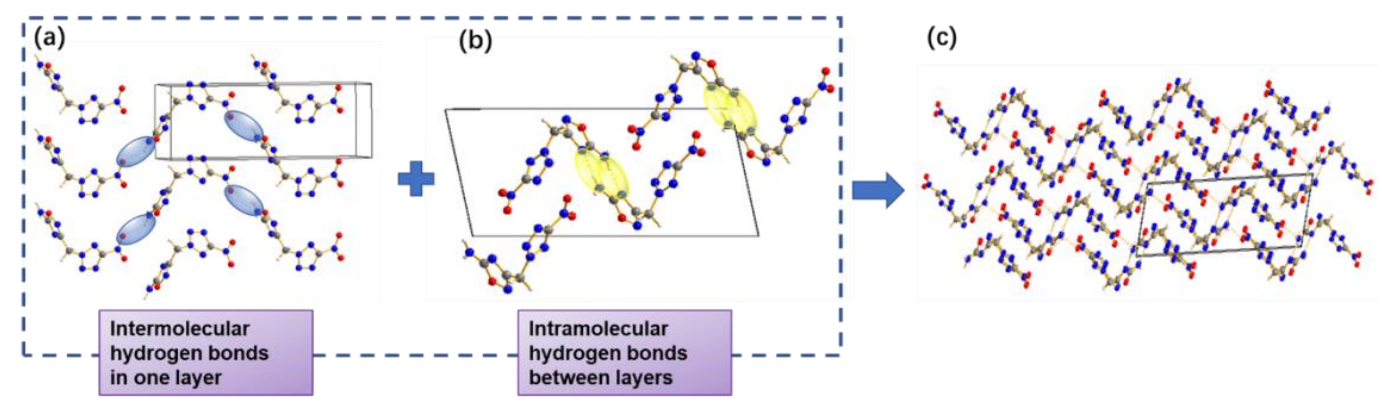

Figure 4. (a) Intermolecular hydrogen bonds in one layer of NTOA; (b) intramolecular hydrogen bonds between adjacent layers of NTOA; (c) stacking diagram of NTOA.

\subsection{Thermal Stabilities}

Figure 5a-c show the DSC-TG traces of NTOM, NTOF and NTOA under a heating rate of $10^{\circ} \mathrm{C} \mathrm{min}^{-1}$. All of the three energetic materials are thermal stable with decomposition points of above $240{ }^{\circ} \mathrm{C}$. NTOM melts at $82.6^{\circ} \mathrm{C}$ and decomposes at $241.1^{\circ} \mathrm{C}$, suggesting its great potential to be used as melt cast explosive. Compared with NTOM, the melting point of NTOF reduced to $71.7^{\circ} \mathrm{C}$, and the decomposition point improved to $241.6^{\circ} \mathrm{C}$ due to the introduction of the $-\mathrm{CF}_{3}$ group. With the help of the abundant inter and intra hydrogen bonds formed in NTOA, the melting point $\left(132.9^{\circ} \mathrm{C}\right)$ and decomposition point $\left(266.0^{\circ} \mathrm{C}\right)$ both increased in comparison with NTOM. In general, the thermal stabilities evaluated from DSC can be summarized as NTOA $\left(266.0^{\circ} \mathrm{C}\right)>\operatorname{NTOF}\left(241.6^{\circ} \mathrm{C}\right)>\operatorname{NTOM}\left(241.1^{\circ} \mathrm{C}\right)$.

In order to obtain further information about the thermal decomposition processes of NTOM, NTOA and NTOF, the reaction kinetic parameters during the heating process were studied by Kissinger's [18] and Ozawa-Doyle's method [19]. The DSC curves at different hating rates $\left(2.5,5,10\right.$ and $\left.15^{\circ} \mathrm{C} \mathrm{min}-1\right)$ were shown in Figure 5. The apparent activation energy $\mathrm{E}$ for the thermal decomposition of NTOM calculated by Kissinger and Ozawa method is $121.54 \mathrm{~kJ} \mathrm{~mol}^{-1}$ and $121.56 \mathrm{~kJ} \mathrm{~mol}^{-1}$, respectively (Table 1). After the introduction of $-\mathrm{CF}_{3}$ and $-\mathrm{NH}_{2}$, the apparent activation energies for the thermal decomposition of NTOF and NTOA were both increased. Notably, the linear correlation coefficients (r) calculated by Kissinger's method and Ozawa's method of the three compounds are very close and greater than 0.98 . Thus, the calculated results are credible and provide a good reference for the thermal safety of NTOM, NTOA and NTOF.

Table 1. Kinetic parameters and enthalpies of thermal decomposition of NTOA, NTOM and NTOF.

\begin{tabular}{|c|c|c|c|c|c|c|c|}
\hline & \multirow{2}{*}{$\beta\left(K \cdot \min ^{-1}\right)$} & \multirow{2}{*}{$T_{\mathrm{p}}(\mathrm{K})$} & \multicolumn{2}{|c|}{$\mathrm{E} /\left(\mathrm{kJ} \cdot \mathrm{mol}^{-1}\right)$} & \multicolumn{2}{|l|}{$\mathbf{r}$} & \multirow{2}{*}{$\begin{array}{c}\begin{array}{c}\lg \\
\left(A_{k} / s^{-1}\right)\end{array} \\
\text { Kissinger }\end{array}$} \\
\hline & & & Kissinger & Ozawa & Kissinger & Ozawa & \\
\hline \multirow[t]{4}{*}{ NTOA } & 2.5 & 521.55 & \multirow{4}{*}{152.72} & \multirow{4}{*}{153.68} & \multirow{4}{*}{0.98549} & \multirow{4}{*}{0.9871} & \multirow{4}{*}{14.55} \\
\hline & 5 & 530.25 & & & & & \\
\hline & 10 & 539.15 & & & & & \\
\hline & 15 & 548.35 & & & & & \\
\hline \multirow[t]{4}{*}{ NTOM } & 2.5 & 491.05 & \multirow{4}{*}{121.54} & \multirow{4}{*}{123.56} & \multirow{4}{*}{0.99565} & \multirow{4}{*}{0.99613} & \multirow{4}{*}{12.2} \\
\hline & 5 & 503.65 & & & & & \\
\hline & 10 & 514.25 & & & & & \\
\hline & 15 & 520.35 & & & & & \\
\hline \multirow[t]{4}{*}{ NTOF } & 2.5 & 498.65 & \multirow{4}{*}{153.05} & \multirow{4}{*}{153.61} & \multirow{4}{*}{0.98583} & \multirow{4}{*}{0.98734} & \multirow{4}{*}{15.32} \\
\hline & 5 & 506.75 & & & & & \\
\hline & 10 & 514.75 & & & & & \\
\hline & 15 & 523.15 & & & & & \\
\hline
\end{tabular}

Notes: $\mathrm{E}$ is the apparent activation energy; $\mathrm{A}_{\mathrm{k}}$ is pre-exponential factor; $\mathrm{r}$ is the liner correlation coefficient. 
(a)

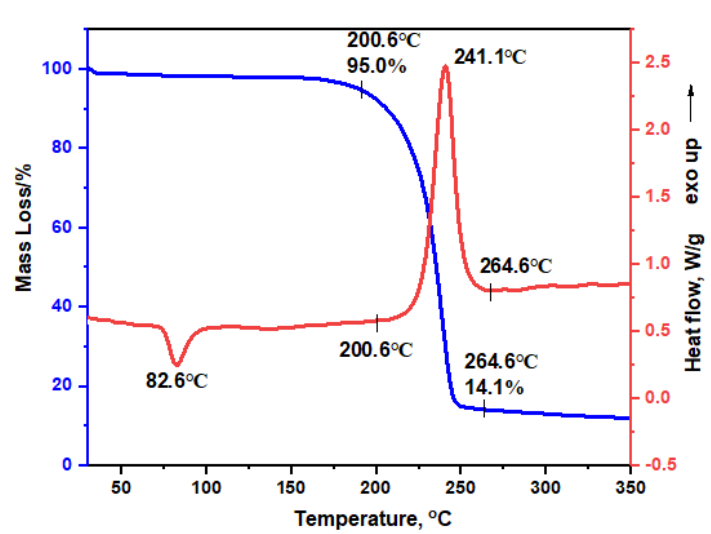

(b)

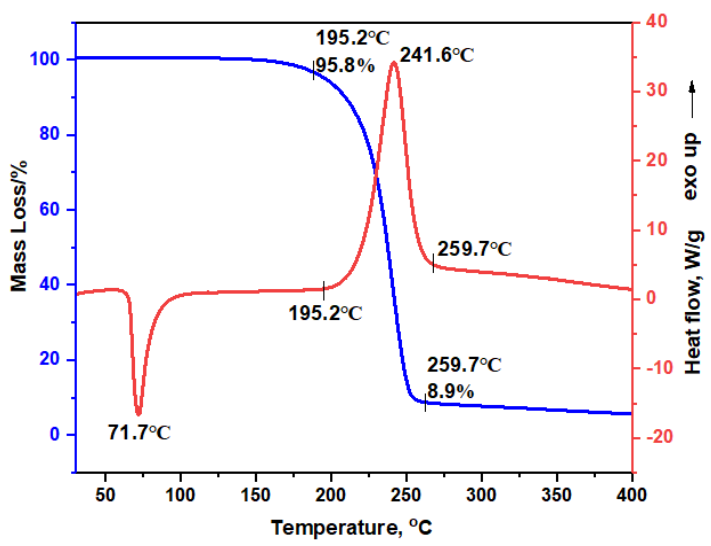

(c)

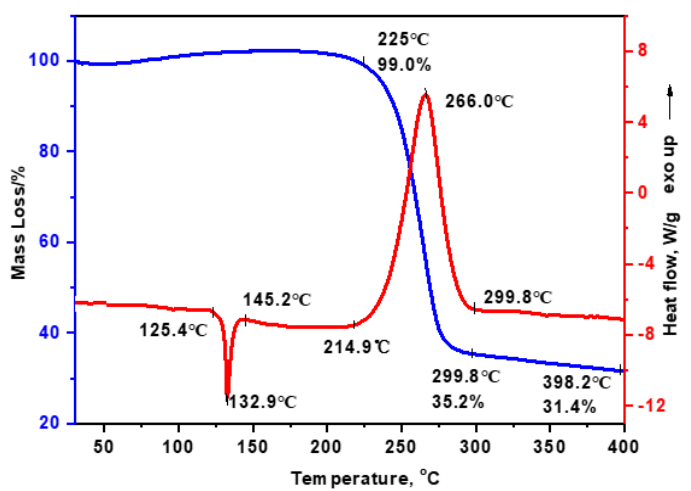

(d)

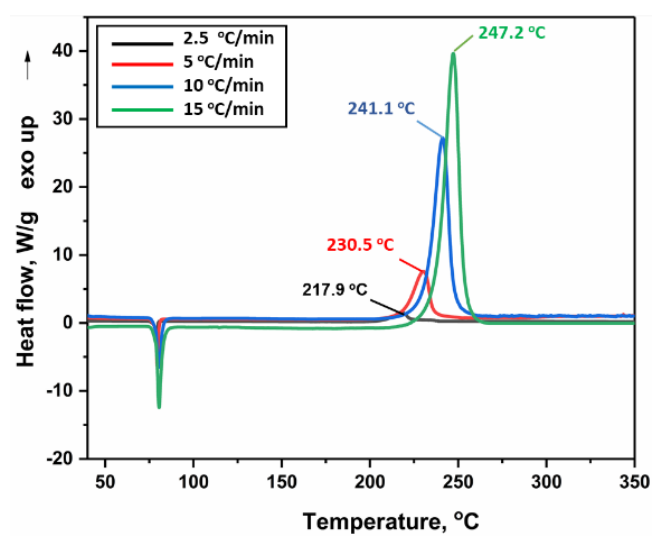

(e)

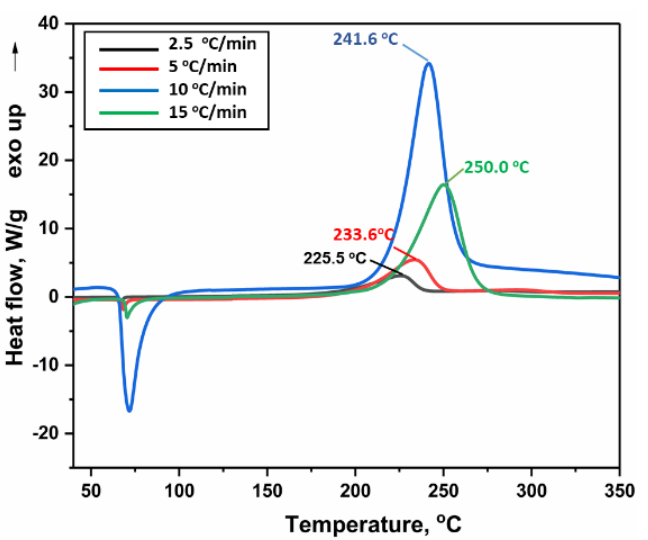

(f)

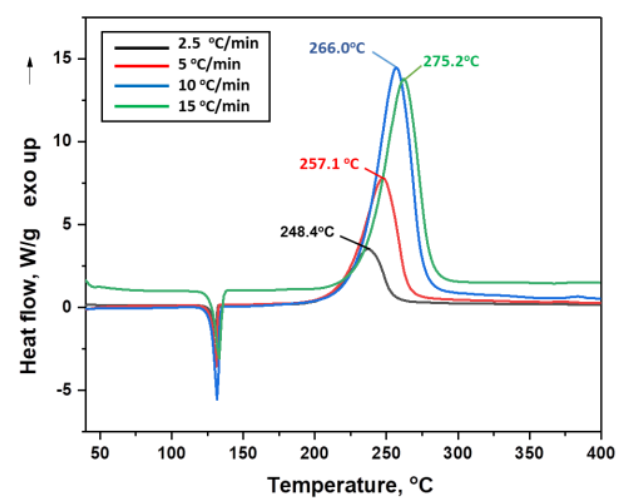

Figure 5. The DSC-TG traces of NTOM (a), NTOF (b) and NTOA (c); the DSC traces of NTOM (d), NTOF (e) and NTOA (f) obtained at different heating rates.

\subsection{Sensitivities}

The sensitivities of NTOM, NTOF and NTOA toward impact and friction were tested using BAM methods, and the results are listed in Table 2. The three compounds possess satisfactory sensitivities with the IS of $>40 \mathrm{~J}$ and FS $>360 \mathrm{~N}$. 
Table 2. Physicochemical properties and detonation performances of NTOA, NTOM, NTOF, TNT and BODN.

\begin{tabular}{cccccc}
\hline Compounds & NTOA & NTOM & NTOF & TNT & BODN [14] \\
\hline$\rho^{(\mathrm{a})}\left(\mathrm{g} / \mathrm{cm}^{3}\right)$ & 1.66 & 1.76 & 1.87 & 1.65 & 1.83 \\
$\Delta_{\mathrm{f}} H^{(\mathrm{b})}(\mathrm{kJ} / \mathrm{mol})$ & 275.8 & 344.9 & -328.8 & -67 & -79.4 \\
$\mathrm{~T}_{\mathrm{m}}(\mathrm{c})\left({ }^{\circ} \mathrm{C}\right)$ & 131.6 & 82.6 & 71.7 & 81 & 84.5 \\
$\mathrm{~T}_{\mathrm{d}}{ }^{(\mathrm{d})}\left({ }^{\circ} \mathrm{C}\right)$ & 256.6 & 241.1 & 261.6 & 295 & 183.4 \\
$\Omega^{(\mathrm{e})}(\%)$ & -60.67 & -0.53 & -0.48 & -74 & -33.3 \\
$\mathrm{D}^{(\mathrm{f})}(\mathrm{m} / \mathrm{s})$ & 7451 & 7909 & 7271 & 6881 & 8180 \\
$P^{(\mathrm{g})}(\mathrm{GPa})$ & 20.89 & 24.80 & 23.66 & 19.5 & 29.4 \\
$\mathrm{IS}^{(\mathrm{h})}(\mathrm{J})$ & $>40$ & $>40$ & $>40$ & 15 & 8.7 \\
$\mathrm{FS}^{(\mathrm{i})}(\mathrm{N})$ & $>360$ & $>360$ & $>360$ & 240 & 282 \\
\hline
\end{tabular}

(a) Density. (b) Heats of formation calculated by Gaussian 09. (c) Melting temperature (endothermic peak). (d) Decomposition temperature at $10^{\circ} \mathrm{C} / \mathrm{min}$ (exothermic peak). (e) Oxygen balance (based on $\mathrm{CO}_{2}$ ) for $\mathrm{C}_{\mathrm{a}} \mathrm{H}_{\mathrm{b}} \mathrm{O}_{\mathrm{c}} \mathrm{N}_{\mathrm{d}}$, $16(\mathrm{c}-(2 \mathrm{a}+0.5 \mathrm{~b})) / \mathrm{MW}, \mathrm{MW}=$ molecular weight. ${ }^{(\mathrm{f})}$ Calculated detonation velocity (EXPLO5 v 6.04). ${ }^{(\mathrm{g})}$ Calculated detonation pressure (EXPLO5 v 6.04). ${ }^{(\mathrm{h})}$ Impact sensitivity evaluated by a standard BAM fall-hammer. ${ }^{(\mathrm{i})}$ Friction sensitivity evaluated by BAM technique.

The impact sensitivity of energetic materials are very closely related to their electrostatic potential (ESP) [20-25]. We calculated the ESP of NTOM, NTOF and NTOA using the Gaussian 09 method at the theoretical level of B3LYP/6-311g $(\mathrm{d}, \mathrm{p})$ before the sensitivity test.

It can be observed from Figure 6 that the negative charges of the three compounds are mainly distributed around nitrotetrazole, while the positive charges are concentrated on the $\mathrm{N}-\mathrm{CH}_{2}-\mathrm{C}$ linkage. Positive charge is distributed on the amino group connected with isofurazan in the NTOA compound and the hydrogen atom connected with isofurazan in NTOM. The trifluoromethyl group in NTOF is distributed with partial positive charge. In most $\mathrm{N}-\mathrm{O}$ compound systems, especially those containing nitro groups, the concentration of more positive charges around $\mathrm{N}$ atoms will result in an imbalance, which will theoretically result in higher impact sensitivity. The $\mathrm{N}$ atoms of the three compounds have no obvious positive charge distribution. Therefore, we believe that the sensitivities of the three compounds are low.

(a)

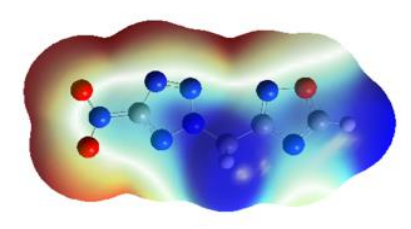

(b)

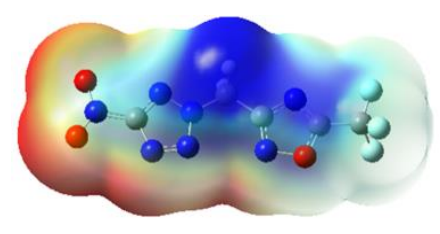

(c)

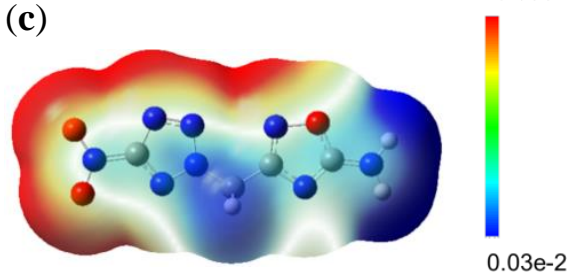

Figure 6. Electrostatic potential of NTOM (a), NTOF (b) and NTOA (c) (B3LYP/ /6-311g(d, p), 0.001 electron/b3 isosurface, energy values -0.03 to $+0.03 \mathrm{H}$ ). Color coding: yellow, slightly negative; green, neutral; turquoise, slightly positive; light blue, positive; dark blue, very positive.

\subsection{Hirshfeld Analysis}

The Hirshfeld surfaces $\left(d_{\text {norm }}\right)$ of NTOM, NTOF and NTOA were calculated by CrystalExplorer [26] (Figure $7 \mathrm{a}-\mathrm{c}$ ). The $3 \mathrm{D} d_{\text {norm }}$ surface was used to identify close intermolecular interactions of compounds. The blue and red regions represent closer and longer contacts, respectively, and the white regions mean the distance of contacts equal to the $\mathrm{v}_{\mathrm{dW}}$ separation with a $d_{\text {norm }}$ value of zero. The green dotted lines represent the hydrogen bonds formed in the molecule, and the red dotted lines are close contacts. 
(a)

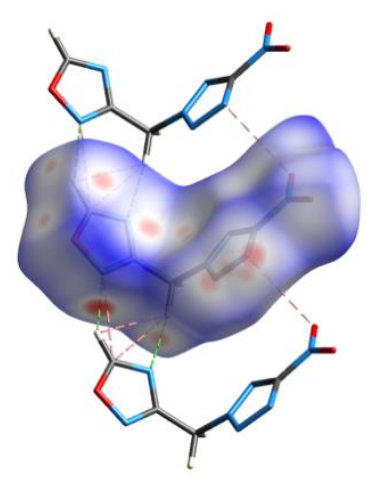

(d)

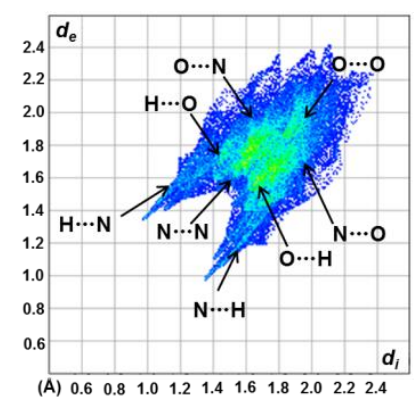

(b)

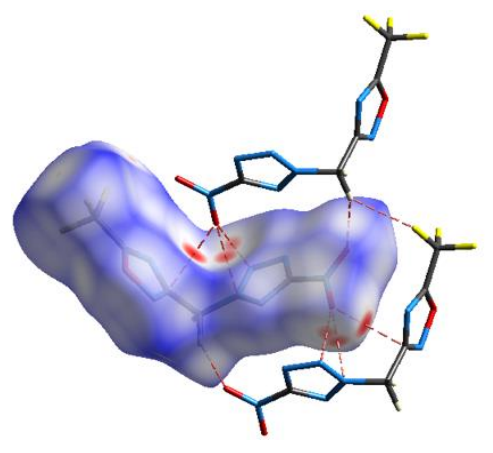

(e)

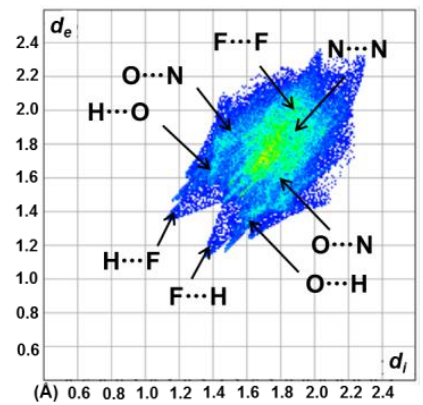

(c)

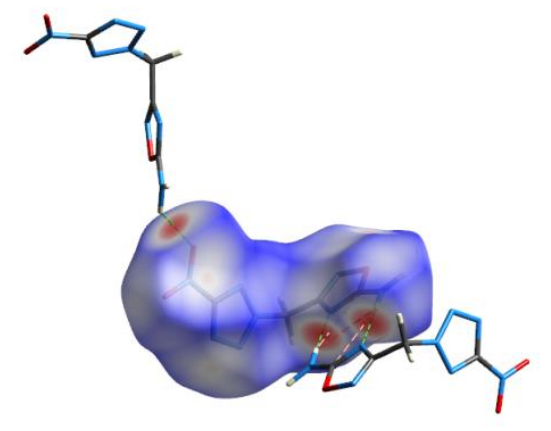

(f)

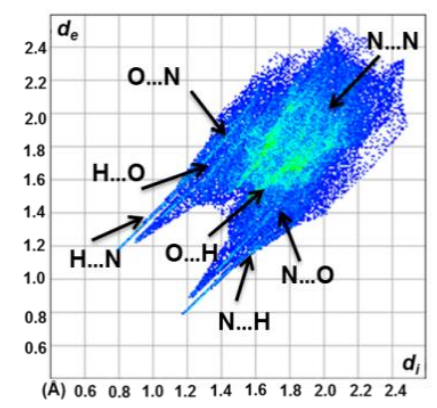

(g)

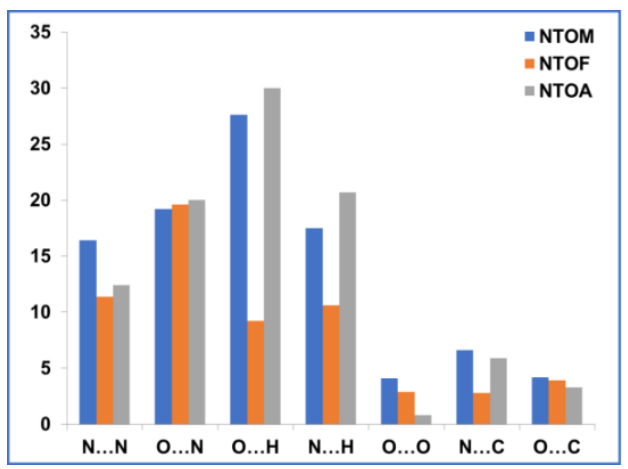

Figure 7. Hirshfeld surface of NTOM (a); Hirshfeld surface of NTOF (b); 2D fingerprint plot of NTOA (c); 2D fingerprint plot of NTOM (d); 2D fingerprint plot of NTOF (e); 2D fingerprint plot of NTOA (f); comparison of the amounts of close interactions in NTOM, NTOF and NTOA $(\mathbf{g})$.

The red dots appeared on the surfaces of NTOM and NTOA are mainly resulted from intermolecular hydrogen bonds formed in the compounds, while the red areas on the surfaces of NTOF are caused by close contacts of the compound. The red dots on NTOM and NTOA attributed to HBs are dark, which indicates the presence of strong hydrogen bonds. As observed from Figure $7 \mathrm{a}-\mathrm{c}$, the three compounds have relatively few "hot spots," indicating that their sensitivities to stimuli are relatively low.

The 2D fingerprint plots clearly illustrate the different contributions of intermolecular interactions (Figure $7 \mathrm{~d}-\mathrm{f}$ ), and the comparison of the amounts of close interactions in NTOM, NTOF and NTOA are shown in Figure 7g. It has been reported that the $\mathrm{O} \ldots \mathrm{H}$ and $\mathrm{N}$... H interactions tend to decrease sensitivities, while the $\mathrm{O} \ldots \mathrm{O}$ interactions usually increase the sensitivity of a compound [27]. The percentage of contribution of $\mathrm{O} \cdots \mathrm{H}$, 
$\mathrm{N} \cdots \mathrm{H}, \mathrm{N} \cdots \mathrm{O}$ and $\mathrm{N} \cdots \mathrm{N}$ type interactions in the total Hirshfeld surface of NTOM are $27.6 \%$, $17.5 \%, 19.2 \%$ and $16.4 \%$, respectively. These values are similar to the results of NTOA (the percentage of contribution of $\mathrm{O} \cdots \mathrm{H}, \mathrm{N} \cdots \mathrm{H}, \mathrm{N} \cdots \mathrm{O}$ and $\mathrm{N} \cdots \mathrm{N}$ type interactions in the total Hirshfeld surface of NTOA is 30\%, 20.7\%, 20\% and $12.4 \%$, respectively). As there are only two $\mathrm{H}$ atoms exist in NTOF, the percentage of contribution of $\mathrm{O} \cdots \mathrm{H}$ and $\mathrm{N} \cdots \mathrm{H}$ interactions are only $9.2 \%$ and $10.6 \%$. The percentage of $\mathrm{N} \cdots \mathrm{O}$ and $\mathrm{N} \cdots \mathrm{N}$ type interactions of NTOF are $19.6 \%$ and $11.4 \%$, respectively. The $\mathrm{N} \cdots \mathrm{C}$ and $\mathrm{O} \cdots \mathrm{C}$ type of interactions contribute asmall amount in the total surface of the three compounds. The $\mathrm{O} \cdots \mathrm{O}$ contact interactions of NTOM, NTOA and NTOF are only $4.1 \%, 0.8 \%$ and $2.9 \%$, which indicate that the three compounds are insensitive to external mechanical stimuli. The Hirshfeld analysis is in good consistency with the ESP analysis and experiment results.

\subsection{Physiochemical Properties and Detonation Performances of NTOM, NTOF and NTOA}

The physiochemical and energetic properties of NTOM, NTOF and NTOA compared with TNT and BODN are summarized in Table 2. Density is one of the most important factors for evaluating the detonation performances of energetic compounds [28,29]. The crystal densities of NTOM, NTOF and NTOA were $1.66,1.76$ and $1.87 \mathrm{~g} / \mathrm{cm}^{3}$, respectively. The introduction of the $-\mathrm{CF}_{3}$ group makes the density of NTOF apparently higher than that of NTOM, while the introduction of $-\mathrm{NH}_{2}$ makes the density of NTOA lower than that of NTOM. Moreover, the densities of these three compounds are higher than that of TNT $\left(1.65 \mathrm{~g} / \mathrm{cm}^{3}\right)$. The solid-state enthalpies of formation of NTOM and NTOA are positive and obtained as $275.8 \mathrm{~kJ} / \mathrm{mol}$ and $344.9 \mathrm{~kJ} / \mathrm{mol}$, respectively. NTOM possesses a detonation velocity of $7909 \mathrm{~m} / \mathrm{s}$ and detonation pressure of $24.80 \mathrm{Gpa}$. The detonation velocity of NTOA is $7451 \mathrm{~m} / \mathrm{s}$, and the detonation pressure is $29.3 \mathrm{GPa}$. However, the solid-state enthalpy of formation of NTOF is negative $(-328.8 \mathrm{~kJ} / \mathrm{mol})$, which renders the detonation pressure and detonation velocity of NTOF lower than those of NTOM and NTOA.

The sensitivities of the three compounds to impact and friction were tested by BAM drop hammer and BAM friction tester. The impact sensitivities of NTOM, NTOA and NTOF are $>40 \mathrm{~J}$ and the friction sensitivities are $>360 \mathrm{~N}$. In comparison with TNT, NTOM and NTOF have better detonation performances, thermal stabilities and sensitivities. In terms of detonation performance, BODN has more outstanding detonation velocity $(D: 8180 \mathrm{~m} / \mathrm{s})$ and detonation pressure ( $P: 29.4 \mathrm{GPa}$ ) than those of NTOM and NTOF. The thermal decomposition temperatures of NTOM and NTOF are greater than $240{ }^{\circ} \mathrm{C}$, which are much higher than that of BODN $\left(T_{\mathrm{d}}: 183.4^{\circ} \mathrm{C}\right)$. Meanwhile, the impact sensitivities of NTOM and NTOF are apparently lower than that of BODN (IS: 8.7 J, FS: $282 \mathrm{~N}$ ).

\section{Experiments}

General caution! Although we have experienced no explosion accidents in synthesis and characterization of these materials, proper protective measures should be adopted.

\subsection{Materials and Measurements}

2-(5-Nitro-2H-tetrazol-2-yl)acetonitrile (1) was prepared according to the literature [17]. Hydroxylamine hydrochloride, sodium bicarbonate, methanol, potassium bicarbonate, cyanogen bromide, trichloroacetic acid (TFA), tetrahydrofuran (THF), triethyl orthoformate $\left((\mathrm{EtO})_{3} \mathrm{CH}\right)$ and $\mathrm{BF}_{3} \cdot \mathrm{Et}_{2} \mathrm{O}$ were commercially available and used without further purification. ${ }^{1} \mathrm{H}$ NMR and ${ }^{13} \mathrm{C}$ NMR of NTAA, NTOA, NTOM and NTOF were recorded on $500 \mathrm{MHz}$ (Bruker AVANCE 500) nuclear magnetic resonance spectrometers. The melting and decomposition points were determined using a differential scanning calorimeter (TA Instruments Company, Model DSC-Q200) at a flow rate of $\mathrm{N}_{2}$ at $50 \mathrm{~mL} \mathrm{~min}^{-1}$. About $0.3 \mathrm{mg}$ of the sample was sealed in aluminium pans for DSC analysis. Infrared spectra were obtained from $\mathrm{KBr}$ pellets on a Nicolet NEXUS870 Infrared spectrometer in the range of $4000 \sim 400 \mathrm{~cm}^{-1}$. Elemental analyses $(\mathrm{C}, \mathrm{H}$ and $\mathrm{N}$ ) were performed on a VARI-El-3 elementary analysis instrument. The impact and friction sensitivities were determined by using the BAM method. 


\subsection{X-ray Crystallography}

The diffraction data of NTOA, NTOM and NTOF were collected on a BRUKER SMART Apex II CCD X-ray diffractometer equipped with a Mo K $\alpha$ radiation $(\lambda=0.71073 \mathrm{~A})$ using the $\omega-\theta$ scan mode. The structures were solved by the direct method using SHELXS-97 and refined with full-matrix least-squares procedures on F2 with SHELXL-97. The crystal data and structure refinement parameters were listed in Table S1 (see Supplementary Materials). The selected bond lengths, bond angles and hydrogen bond data were summarized in Tables S2-S7. The crystal structures of NTOM, NTOF and NTOA have been deposited with the Cambridge Crystallographic Data Centre (CCDC), under deposition numbers 2,114,990, 2,114,991 and 1,947,762. These data can be obtained free of charge from The Cambridge Crystallographic Data Centre via https:/ / www.ccdc.cam.ac.uk/ (accessed on 11 October 2021).

\subsection{Synthesis of NTAA}

Compound $1(0.46 \mathrm{~g}, 3.0 \mathrm{mmol})$, hydroxylamine hydrochloride $(0.32 \mathrm{~g}, 4.6 \mathrm{mmol})$ and $\mathrm{NaHCO}_{3}(0.39 \mathrm{~g}, 4.6 \mathrm{mmol})$ were added to $\mathrm{MeOH}(5 \mathrm{~mL})$. After refluxing the reaction solution for $2 \mathrm{~h}$, the inorganic salt was removed by filtration, and the solvent was evaporated to provide a yellow solid NTAA $(0.54 \mathrm{~g}, 96 \%) .{ }^{1} \mathrm{H}$ NMR $\left(500 \mathrm{MHz}\right.$, DMSO- $\left.d_{6}\right): \delta \mathrm{ppm}: 5.460$ $(\mathrm{s}, 2 \mathrm{H}, \mathrm{CH}), 5.853(\mathrm{~s}, 2 \mathrm{H}, \mathrm{NH}), 9.640(\mathrm{~s}, 1 \mathrm{H}, \mathrm{OH}) ;{ }^{13} \mathrm{C}$ NMR $\left(125 \mathrm{MHz}, \mathrm{DMSO}-d_{6}\right): \delta \mathrm{ppm}:$ $55.103,146.499,166.254$; IR v: 3485, 3382, 2871, 2813, 1678, 1598, 1555, 1476, 1420, 1325, 910, $844,775,705,659 \mathrm{~cm}^{-1}$; elemental analysis calculated (\%) for compound 2: C 19.54, H 2.72, N 52.44; found: C19.26, H 2.69, N 52.40.

\subsection{Synthesis of NTOA}

NTAA $(0.3 \mathrm{~g}, 1.6 \mathrm{mmol})$ was added to a solution of $\mathrm{KHCO}_{3}(0.53 \mathrm{~g}, 5.3 \mathrm{mmol})$ in water $(10 \mathrm{~mL})$. The reaction solution was heated to clear $\left(45^{\circ} \mathrm{C}\right)$, and cooled to room temperature. $\mathrm{BrCN}(0.26 \mathrm{~g}, 2.4 \mathrm{mmol})$ was added portionwise. The reaction solution was stirred overnight; then, the light brown solid was formed and filtered. The filter cake was washed with a small amount of cold water and diethyl ether and dried naturally to provide the product NTOA $(0.2 \mathrm{~g}, 62 \%) .{ }^{1} \mathrm{H}$ NMR (500 MHz, DMSO- $\left.d_{6}\right): \delta \mathrm{ppm}: 8.093(\mathrm{~s}, 2 \mathrm{H}, \mathrm{NH})$, 6.169 (s, $2 \mathrm{H}, \mathrm{CH}) ;{ }^{13} \mathrm{C}$ NMR $\left(125 \mathrm{MHz}, \mathrm{DMSO}-d_{6}\right): \delta \mathrm{ppm}$ : 173.022, 166.540, 164.323, 50.176; IR v: 3421, 3361, 3139, 3020, 2979, 1678, 1565, 1484, 1429, 1341, 1321, 848, 757, $634 \mathrm{~cm}^{-1}$; elemental analysis calculated (\%) for compound NTOA: C 22.65, H 1.90, N 52.82; found: C 22.60, H 1.92, N 53.01.

\subsection{Synthesis of NTOM}

Triethyl orthoformate $(3.96 \mathrm{~g}, 26.7 \mathrm{mmol})$ and NTAA $(0.5 \mathrm{~g}, 2.67 \mathrm{mmol})$ were added into three-necked flask, then $\mathrm{BF}_{3} \cdot \mathrm{Et}_{2} \mathrm{O}$ was added dropwise at room temperature. After $4 \mathrm{~h}$, the reaction solution was poured into ice, white solid was precipated and filtered. Washed with small amount of cold water, $0.43 \mathrm{~g}$ NTOM was obtained with a yield of $82 \% .{ }^{13} \mathrm{C}$ NMR (125 MHz, $\left.\mathrm{CDCl}_{3}-d_{6}\right): \delta \mathrm{ppm}: 49.36\left(\mathrm{CH}_{2}\right), 162.42,166.45$ (tetrazol and oxadiazole circle); ${ }^{1} \mathrm{H}$ NMR (500 MHz, $\left.\mathrm{CDCl}_{3}-d_{6}\right)$ : $\delta$ ppm: 6.16 (s, CH2), 8.85(s, CH); IR v: 3129, 3022, $2975,1559,1483,1419,1322,1279,1103,1030,848,618 \mathrm{~cm}^{-1}$; elemental analysis calculated (\%) for compound NTOM: C 24.37, H 1.53, N 49.74; found: C 24.41, H 1.51, N 49.70.

\subsection{Synthesis of NTOF}

NTAA ( $0.72 \mathrm{~g}, 3.85 \mathrm{mmol})$ was added to dry THF $(4 \mathrm{~mL})$, then TFAA $(2.4 \mathrm{~g}, 11.55 \mathrm{mmol})$ was added dropwise. The solution was heated to reflux for $24 \mathrm{~h}$. Twenty-five percent aqueous ammonia solution was added to neutralize the reaction solution to $\mathrm{pH}=7-8$. Saturated $\mathrm{NaCl}$ aqueous solution was added, and ethyl acetate was used for extraction. The solvent evaporated, and $0.8 \mathrm{~g}$ NTOF was obtained with a yield of $79 \% .{ }^{13} \mathrm{C} \mathrm{NMR}(500 \mathrm{MHz}$, $\left.\mathrm{CDCl}_{3}-d_{6}\right): \delta \mathrm{ppm}: 49.17\left(\mathrm{CH}_{2}\right), 115.01\left(-\mathrm{CF}_{3}\right), 164.10,167.80$ (tetrazol and oxadiazole circle); ${ }^{1} \mathrm{H}$ NMR $\left(500 \mathrm{MHz}, \mathrm{CDCl}_{3}-d_{6}\right): \delta$ ppm: $6.23\left(\mathrm{~s}, \mathrm{CH}_{2}\right) ;{ }^{19} \mathrm{~F} \mathrm{NMR}\left(470.5 \mathrm{MHz}, \mathrm{CDCl}_{3}-d_{6}\right): \delta$ ppm: $-65.24\left(-\mathrm{CF}_{3}\right)$; IR v: 3448, 3047, 2986, 2878, 1609, 1568, 1482, 1347, 1184, 1449, 995, 
846, 773, $653 \mathrm{~cm}^{-1}$; elemental analysis calculated (\%) for compound NTOF: C 22.65, H 0.76; found: C 22.50, H 0.77 .

\section{Conclusions}

In this study, a new structural type for melt cast materials was designed by linking, for the first time, a nitrotetrazole ring with 1,2,4-oxadiazole through a $\mathrm{N}-\mathrm{CH}_{2}-\mathrm{C}$ bridge. Three $\mathrm{N}-\mathrm{CH}_{2}-\mathrm{C}$-bridged energetic compounds, namely NTOM, NTOF and NTOA, were synthesized starting from 2-(5-nitro-2H-tetrazole-2-yl)acetonitrile. The three compounds were fully characterized by NMR, IR spectroscopy and elemental analysis. In addition, the single crystals of NTOM, NTOF and NTOA were successfully obtained and investigated by using single-crystal X-ray diffraction. Crystal densities of the three compounds are in the range of $1.66 \mathrm{~g} / \mathrm{cm}^{3}$ (NTOA) $1.87 \mathrm{~g} / \mathrm{cm}^{3}$ (NTOF). Calculated detonation velocities are between $7271 \mathrm{~m} / \mathrm{s}$ (NTOF) and $7909 \mathrm{~m} / \mathrm{s}$ (NTOM). The impact sensitivities are $>40 \mathrm{~J}$, and the friction sensitivities are $>360 \mathrm{~N}$. NTOM, NTOF and NTOA are thermally stable with decomposition points above $240{ }^{\circ} \mathrm{C}$. These compounds possess good thermal stabilities. The melting points of NTOM and NTOF are $82.6^{\circ} \mathrm{C}$ and $71.7^{\circ} \mathrm{C}$, respectively. Hence, these compounds hold the potential to be used as melt cast materials with better performances than TNT. This study demonstrates that the construction of $\mathrm{N}-\mathrm{CH}_{2}-\mathrm{C}$ linkage in heterocycles is an effective strategy to reduce sensitivity and improve thermal stabilities of energetic materials.

Supplementary Materials: The following are available online, Table S1: Crystal data and structure refinement parameters for NTOM, NTOF and NTOA, Tables S2-S4: Selected bond lengths ( $\AA$ ) and bond angles $\left({ }^{\circ}\right)$ of NTOM, NTOF and NTOA, Tables S5-S7: Hydrogen bond lengths $(\AA)$ and bong angles $\left({ }^{\circ}\right)$ of NTOM, NTOF and NTOA, Figure S1: ${ }^{1} \mathrm{H}$ NMR spectrum of NTAA, Figure S2: ${ }^{13} \mathrm{CNMR}$ spectrum of NTAA, Figure S3: ${ }^{1} \mathrm{H}$ NMR spectrum of NTOA, Figure S4: ${ }^{13} \mathrm{C}$ NMR spectrum of NTOA, Figure S5: ${ }^{1} \mathrm{H}$ NMR spectrum of NTOM, Figure S6: ${ }^{13} \mathrm{C}$ NMR spectrum of NTOM, Figure S7: ${ }^{1} \mathrm{H}$ NMR spectrum of NTOF, Figure S8: ${ }^{13} \mathrm{C}$ NMR spectrum of NTOF, Figure S9: ${ }^{19} \mathrm{~F}$ NMR spectrum of NTOF, Figures S10-S12: IR spectrum of NTOA, NTOM, NTOF.

Author Contributions: Conceptualization, J.Z., F.B. and B.W.; methodology, J.Z. and Q.X.; formal analysis, J.Z. and F.B.; investigation, J.Z.; resources, F.B. and Q.X.; writing - original draft preparation, J.Z.; writing - review and editing, J.Z., F.B. and B.W.; supervision, Z.Y. and B.W.; Funding acquisition, B.W. All authors have read and agreed to the published version of the manuscript.

Funding: This research was funded by the National Natural Science Foundation of China (Grant No. 21805224).

Institutional Review Board Statement: Not applicable.

Informed Consent Statement: Not applicable.

Data Availability Statement: Not applicable.

Conflicts of Interest: The authors declare no conflict of interest.

Sample Availability: Samples of the compounds are available from the authors.

\section{References}

1. Ravi, P.; Badgujar, D.M.; Gore, G.M.; Tewari, S.P.; Sikder, A.K. Review on Melt Cast Explosives. Propellants Explos. Pyrotech. 2011, 36, 393-403. [CrossRef]

2. Johnson, E.C.; Sabatini, J.J.; Chavez, D.E.; Wells, L.A.; Banning, J.E.; Sausa, R.C.; Byrd, E.; Orlicki, J.A. Bis(Nitroxymethylisoxazolyl) Furoxan: A Promising Standalone Melt-Castable Explosive. ChemPlusChem 2020, 85, 237-239. [CrossRef]

3. Hsu, D.W.; Wang, T.I.; Huang, D.J.; Pao, Y.J.; Lin, Y.A.; Cheng, T.W.; Liang, S.H.; Chen, C.Y.; Kao, G.M.; Sheu, Y.T.; et al. Copper promotes E. coli laccase-mediated TNT biotransformation and alters the toxicity of TNT metabolites toward Tigriopus japonicas. Ecotoxicol. Environ. Saf. 2019, 173, 452-460. [CrossRef] [PubMed]

4. Esteve-Núñez, A.; Caballero, A.; Ramos, J.L. Biological Degradation of 2,4,6-Trinitrotoluene. Microbiol. Mol. Biol. Rev. 2001, 65, 335-352. [CrossRef] [PubMed]

5. Sabatini, J.J.; Oyler, K.D. Recent Advances in the Synthesis of High Explosive Materials. Crystals 2015, 6, 5. [CrossRef] 
6. Johnson, E.C.; Bukowski, E.J.; Sabatini, J.J.; Sausa, R.C.; Byrd, E.F.; Garner, M.A.; Chavez, D.E. Bis(1,2,4-oxadiazolyl)Furoxan: A Promising Melt-Castable Eutectic Material of Low Sensitivity. ChemPlusChem 2019, 84, 319. [CrossRef] [PubMed]

7. Yan, C.; Wang, K.; Liu, T.; Yang, H.; Cheng, G.; Zhang, Q. Exploiting the energetic potential of 1,2,4-oxadiazole derivatives: Combining the benefits of a 1,2,4-oxadiazole framework with various energetic functionalities. Dalton Trans. 2017, 46, 14210-14218. [CrossRef]

8. Kettner, M.A.; Karaghiosoff, K.; Klapötke, T.M.; Sućeska, M.; Wunder, S. 3, 3'-Bi (1,2,4-oxadiazoles) Featuring the Fluorodinitromethyl and Trinitromethyl Groups. Chem. Eur. J. 2014, 20, 7622-7631. [CrossRef]

9. Kettner, M.A.; Klapötke, T.M. 5,5'-Bis-(trinitromethyl)-3,3'-bi-(1,2,4-oxadiazole): A stable ternary CNO-compound with high density. Chem. Commun. 2014, 50, 2268-2270. [CrossRef]

10. Kettner, M.A.; Klapötke, T.M.; Witkowski, T.G.; von Hundling, F. Synthesis, Characterisation and Crystal Structures of Two Bi-oxadiazole Derivatives Featuring the Trifluoromethyl Group. Chem. Eur. J. 2015, 21, 4238-4241. [CrossRef] [PubMed]

11. Tsyshevsky, R.; Pagoria, P.F.; Zhang, M.; Racoveanu, A.; Parrish, D.A.; Smirnov, A.; Kuklja, M.M. Comprehensive End-to-End Design of Novel High Energy Density Materials: I. Synthesis and Characterization of Oxadiazole Based Heterocycles. J. Phys. Chem. C 2017, 121, 23853-23864. [CrossRef]

12. Pagoria, P.F.; Zhang, M.-X.; Zuckerman, N.B.; DeHope, A.J.; Parrish, D.A. Synthesis and characterization of multicyclic oxadiazoles and 1-hydroxytetrazoles as energetic materials. Chem. Heterocycl. Compd. 2017, 53, 760-778. [CrossRef]

13. Fershtat, L.L.; Ananyev, I.V.; Makhova, N.N. Efficient assembly of mono- and bis (1,2,4-oxadiazol-3-yl) furoxan scaffolds via tandem reactions of furoxanylamidoximes. RSC Adv. 2015, 5, 47248-47260. [CrossRef]

14. Johnson, E.C.; Sabatini, J.J.; Chavez, D.E.; Sausa, R.C.; Byrd, E.; Wingard, L.A.; Guzmàn, P.E. Bis (1,2,4-oxadiazole) bis (methylene) Dinitrate: A High-Energy Melt-Castable Explosive and Energetic Propellant Plasticizing Ingredient. Org. Process. Res. Dev. 2018, 22, 736-740. [CrossRef]

15. Ma, Q.; Zhang, Z.; Yang, W.; Li, W.; Ju, J.; Fan, G. Strategies for constructing melt-castable energetic materials: A critical review. Energ. Mater. Front. 2021, 2, 69-85. [CrossRef]

16. Lu, T.; Wang, C.; Wang, G.; Wang, S.; Song, J.; Yin, H.; Fan, G.; Chen, F.-X. 1,2,4-Oxadiazole-derived polynitro energetic compounds with sensitivity reduced by a methylene bridge. New J. Chem. 2019, 43, 13330-13333. [CrossRef]

17. Zhang, J.R.; Bi, F.Q.; Wang, B.Z.; Zhai, L.J. Synthesis and Characterization of Methylene-bridged Energetic Compound: 3-(5-nitro2H-tetrazol-2-yl)-1,2,4- Oxadiazol-5-amine (NTOA). In Proceedings of the 50th International Annual Conference of Fraunhofer ICT, Karlsruhe, Germany, 25-28 June 2019; Volume 76.

18. Kissinger, H.E. Variation of peak temperature with heating rate in differential thermal analysis. J. Res. Natl. Bur. Stand. 1956, 57, 217-221. [CrossRef]

19. Ozawa, T. Kinetic analysis of derivative curves in thermal analysis. J. Therm. Anal. Calorim. 1970, 2, 301-324. [CrossRef]

20. Ren, F.-D.; Cao, D.-L.; Shi, W.-J.; Gao, H.-F. A theoretical prediction of the relationships between the impact sensitivity and electrostatic potential in strained cyclic explosive and application to H-bonded complex of nitrocyclohydrocarbon. J. Mol. Model. 2016, 22, 1-8. [CrossRef] [PubMed]

21. Cao, Y.; Lin, X.; Yang, J.; Gong, X.; Fan, G.; Huang, H. Synthesis and performance study of methylene-bridged bis(nitramino-1,2,4oxadiazole) and its energetic salts. New J. Chem. 2019, 43, 5441-5447. [CrossRef]

22. Murray, J.S.; Politzer, P.; Bolduc, P.R. A Relationship Between Impact Sensitivity and the Electrostatic Potentials at the Midpoints of C-NO2 Bonds in Nitroaromatics. Chem. Phys. Lett. 1990, 168, 135-139. [CrossRef]

23. Murray, J.S.; Concha, M.C.; Politzer, P. Links between surface electrostatic potentials of energetic molecules, impact sensitivities and C-NO2/N-NO2bond dissociation energies. Mol. Phys. 2009, 107, 89-97. [CrossRef]

24. Klapötke, T.M.; Nordheider, A.; Stierstorfer, J. Synthesis and reactivity of an unexpected highly sensitive 1-carboxymethyl-3diazonio-5-nitrimino-1,2,4-triazole. New J. Chem. 2012, 36, 1463-1468. [CrossRef]

25. Murray, J.S.; Lane, P.; Politzer, P. Relationships between impact sensitivities and molecular surface electrostatic potentials of nitroaromatic and nitroheterocyclic molecules. Mol. Phys. 1995, 85, 1-8. [CrossRef]

26. Chan, E.J.; Grabowsky, S.; Harrowfield, J.M.; Shi, M.W.; Skelton, B.W.; Sobolev, A.N.; White, A.H. Hirshfeld surface analysis of crystal packing in aza-aromatic picrate salts. CrystEngComm 2014, 16, 4508-4538. [CrossRef]

27. Zhai, L.; Bi, F.; Luo, Y.; Sun, L.; Huo, H.; Zhang, J.; Zhang, J.; Wang, B.; Chen, S. Exploring the highly dense energetic materials via regiochemical modulation: A comparative study of two fluorodinitromethyl-functionalized herringbone trifuroxans. Chem. Eng. J. 2020, 391, 123573. [CrossRef]

28. Wei, H.; He, C.; Zhang, J.; Shreeve, J.M. Combination of 1,2,4-Oxadiazole and 1,2,5-Oxadiazole Moieties for the Generation of High-Performance Energetic Materials. Angew. Chem. Int. Ed. 2015, 54, 9367-9371. [CrossRef]

29. Kamlet, M.J.; Jacobs, S.J. Chemistry of Detonations. I. A Simple Method for Calculating Detonation Properties of C-H-N-O Explosives. J. Chem. Phys. 1968, 48, 23-35. [CrossRef] 